\title{
Chemotherapy alone versus definitive concurrent chemoradiotherapy for cT4b esophageal squamous cell carcinoma: a population-based study
}

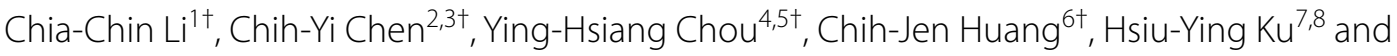
Chun-Ru Chien ${ }^{1,9,10^{*}}$

\begin{abstract}
Background: The role of radiotherapy for cT4bNanyM0 esophageal squamous cell carcinoma (ESqCC) is relatively unclear, with both chemotherapy (C/T) alone and definitive concurrent chemoradiotherapy (dCCRT) being treatment options in the current guidelines. We aimed to compare the survival of dCCRT versus $C / T$ for these patients via a population-based approach.

Methods: Eligible cT4b ESqCC patients diagnosed between 2011 and 2017 were identified via the Taiwan Cancer Registry. We used propensity score (PS) weighting to balance the observable potential confounders between groups. The hazard ratio (HR) of death and incidence of esophageal cancer mortality (IECM) were compared between dCCRT and C/T. We also evaluated OS in subgroups of either low or standard radiotherapy doses.

Results: Our primary analysis consisted of 247 patients in whom covariates were well balanced after PS weighing. The HR for death when dCCRT was compared with C/T was 0.36 (95\% confidence interval $0.24-0.53, P<0.001$ ). Similar results were found for IECM. Statistical significance was only observed in the standard RT dose but not in the low dose in subgroup analyses.

Conclusions: In this population-based nonrandomized study of cT4bNanyMO ESqCC patients from Asia (Taiwan), we found that the use of radiotherapy with chemotherapy was associated with better overall survival than chemotherapy alone. Further studies (especially RCTs) are needed to confirm our findings.
\end{abstract}

Keywords: Chemotherapy, Definitive concurrent chemoradiotherapy, Esophageal squamous cell carcinoma

\section{Background}

Esophageal cancer is one of the leading cancer deaths worldwide, including in Taiwan [1]. The predominant histology was adenocarcinoma in Western countries and

\footnotetext{
${ }^{*}$ Correspondence: d16181@gmail.com

${ }^{\dagger}$ Chia-Chin Li, Chih-Yi Chen, Ying-Hsiang Chou and Chih-Jen Huang have contributed equally to this work

1 Department of Radiation Oncology, China Medical University Hsinchu Hospital, Hsinchu, Taiwan

Full list of author information is available at the end of the article
}

squamous cell carcinoma in Asians [1,2].

For locally advanced esophageal squamous cell carcinoma (LA-ESqCC), radiotherapy is an important treatment modality [3-5]. However, the role of radiotherapy for cT4bNanyM0 is relatively unclear. Both chemotherapy $(\mathrm{C} / \mathrm{T})$ alone and definitive concurrent chemoradiotherapy (dCCRT) are treatment options for cT4b ESqCC in the current North American guidelines [3]. This is possibly related to concerns over radiotherapy-related complications for cT4b disease [6]. 
Due to the above concerns over the use of radiotherapy for cT4b LA-ESqCC and few relevant studies [7], our study aimed to compare the survival of chemotherapy alone versus definitive concurrent chemoradiotherapy for cT4bNanyM0 esophageal squamous cell carcinoma patients via a population-based approach.

\section{Methods}

Data

We used the Taiwan Cancer Registry (TCR) as the data source in this study. The quality of TCR was reported to be one of the highest-quality cancer registries in the world $[8,9]$.

\section{Study population}

We identified esophageal cancers diagnosed between 2011 and 2017 from TCR. The inclusion criteria of our study were (a) ESqCC patients with clinical stage cT4bNanyM0 by the 7th American Joint Committee on Cancer (AJCC); (b) age 20-75 years old; and (c) patients treated with either $\mathrm{C} / \mathrm{T}$ without radiotherapy or surgery (C/T group) or CCRT without surgery (dCCRT group) according to records in TCR. In the dCCRT group, we only included those who received a conventional fractionated external beam radiotherapy dose $\leq 70$ Gy [5, 10, 11]. The exclusion criteria were (a) those with multiple treatment records in TCR and (b) those with prior cancer(s). These inclusion/exclusion criteria were modified from a relevant ongoing trial [12].

\section{Covariates}

We included the following covariates as modified from recent relevant studies and our clinical and research experiences [7, 12-14]. Patient demographics (age, sex, residency), patient characteristics [body mass index (BMI), drinking, smoking], disease characteristics (N-stage, tumor location), and the use of positron emission tomography (PET) were defined as follows. Patient residency region was classified as 'northern Taiwan' or 'non-north' Smoking, drinking and the use of PET were classified as yes or no. The clinical N-stage was classified as ' 0 ' or ' $1-3$ '. Tumor location was classified as 'cervical' or 'noncervical'.

\section{Statistical and subgroup analyses}

The primary outcome of interest was overall survival (OS). We also evaluated the impact of intervention $(\mathrm{C} / \mathrm{T}$ vs dCCRT) on the incidence of esophageal cancer mortality (IECM). We adopted the propensity score (PS) approach and used PS weighting (PSW) as the framework for analyses, as advocated in the literature [15-17]. We estimated the probability of receiving dCCRT (vs. $\mathrm{C} / \mathrm{T}$ ) with a logistic regression model based on all the above covariates (i.e., age, sex, residency, BMI, drinking, smoking, N-stage, tumor location, and the use of PET) and then assessed the balance of covariates between groups after PSW using overlap weight $[18,19]$ via the standardized difference (SDif) $[15,20,21]$. We compared the hazard ratio (HR) of death between the dCCRT group and $\mathrm{C} / \mathrm{T}$ group groups during the entire follow-up period via the Cox proportional hazards model in the weighted sample for point estimation and used the bootstrap method to estimate the $95 \%$ confidence interval $(95 \% \mathrm{CI})[18,22,23]$. We used the E-value to assess the robustness of our finding regarding potential unmeasured confounder(s), as suggested in the literature [2426], because the PS approach can only be valid under the assumption of no unmeasured confounder(s). We took a competing risk approach to compare IECM between groups [27]. We performed two separate PSW subgroup analyses (SA) according to the radiotherapy dose $(<50$ Gy vs $50-70$ Gy) because 50 Gy was the recommended minimal radiotherapy dose for dCCRT in the treatment guidelines [3-5].

\section{Results \\ Study population}

We identified 247 patients (56 for the C/T group and 191 for the dCCRT group) as our primary study population, as depicted in Fig. 1 [STROBE]. We achieved covariate balance after PSW, although some imbalance was seen before PSW, as shown in Table 1. After a median follow-up of 7 months (range 0.4-107), death occurred in 56 patients in the $C / T$ group and 173 patients in the dCCRT group. The median follow-up for survivors was 61 months (range 29-107).

\section{Primary analysis}

The overlap weight-adjusted OS curves are shown in Fig. 2. The 1/2/5-year OS rates for both groups were $4 / 2 / 0 \%$ (C/T group) and 28/14/10\% (dCCRT group), respectively. The median OS (month) was 4 for the $\mathrm{C} / \mathrm{T}$ group and 8 for the dCCRT group. When the dCCRT group was compared to the $\mathrm{C} / \mathrm{T}$ group, the HR of death was 0.36 [95\% confidence interval $(95 \% \mathrm{CI}) \quad 0.24-0.53$, $P \leq 0.001]$. The observed HR of 0.36 for OS could be explained by an unmeasured confounder that was associated with both selections of treatment ( $\mathrm{C} / \mathrm{T}$ vs $\mathrm{dCCRT})$ and outcome (live vs death) by a risk ratio of 3.44 (E-value) fold each, but weaker confounding could not do so [26]. The HR for IECM was 0.49 (95\% CI $0.29-0.83$, $P=0.007)$.

\section{Subgroup analyses}

In both SA-1 and SA-2, we achieved covariate balance after PSW, although some imbalance was seen 


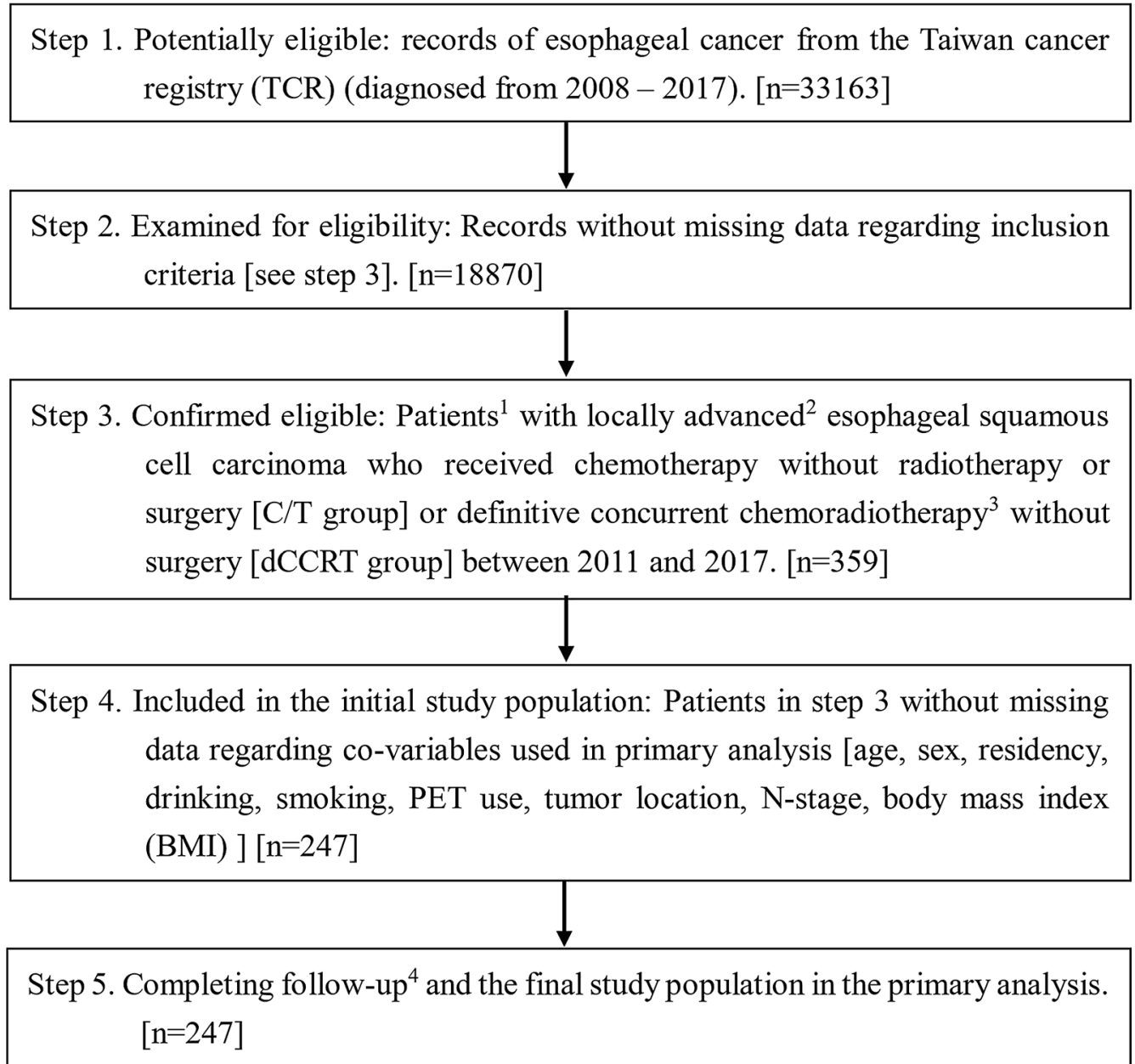

Fig. 1 STROBE study flowchart and the number of individuals at each stage of the study. ${ }^{1}$ We only included those treated (classes 1-2) with only one record to ensure data consistency. ${ }^{2}$ The Seventh American Joint Committee on Cancer staging clinical stage cT4bNanyM0. ${ }^{3} \mathrm{Conventional}$ fractionated external beam radiotherapy dose $\leq 70 \mathrm{~Gy}$ at $1.8-2 \mathrm{~Gy} /$ fraction. ${ }^{4}$ Without missing information in the TCR and death registry

before PSW, as shown in Tables 2 and 3. Comparisons between the $\mathrm{dCCRT}$ group and the $\mathrm{C} / \mathrm{T}$ group revealed significantly better OS for dCCRT patients with a standard dose ( $\geq 50 \mathrm{~Gy})$ but not for those with a low dose ( $<50$ Gy); the HR of death is summarized in Table 4. For those who received a standard dose ( $\geq 50 \mathrm{~Gy}$ ), the rate of death within 3 months of completing RT was $3.7 \%$.

\section{Discussion}

In this population-based nonrandomized study of cT4bNanyM0 esophageal squamous cell carcinoma patients from Asia (Taiwan), we found that the use of radiotherapy with chemotherapy was associated with better overall survival than chemotherapy alone. To our knowledge, this is the 1st study on this topic.

A similar trend regarding the role of radiotherapy in these patients was reported in a North American cancer registry-based study in 2019 [7]. The reported median OS for $\mathrm{C} / \mathrm{T}$ and chemoradiotherapy was 6 and 12.7 months, respectively. However, this study included both SqCC and adenocarcinoma patients, and relevant results specific to SqCC were not reported. We further searched in Dec 2020 using the keywords "((esophageal squamous cell carcinoma) AND (cT4b))" in PubMed but found no additional relevant studies.

The interpretation of our study seems straightforward due to the potential role of radiotherapy in definitive treatment for LA-ESqCC, as observed in previous randomized controlled trials (RCTs) [28, 29]. However, our study somehow relieved the concern for OS (although the concern for toxicity remained) after radiotherapy for this specific population [cT4b], as reflected in the current North American guidelines [3]. However, our study should also be interpreted with caution given its 
Table 1 Patient characteristics of the study population in the primary analysis

\begin{tabular}{|c|c|c|c|c|c|c|}
\hline & \multicolumn{2}{|l|}{$\mathrm{C} / \mathrm{T}$ Group $(\mathrm{n}=56)$} & \multicolumn{2}{|l|}{ dCCRT Group $(n=191)$} & \multicolumn{2}{|c|}{$\begin{array}{l}\text { Standardized difference } \\
\text { (rounded) }^{\mathrm{a}}\end{array}$} \\
\hline & Number or mean $(S D)^{a}$ & $(\%)^{\mathrm{a}}$ & Number or mean (SD) ${ }^{a}$ & $(\%)^{\mathrm{a}}$ & Before PSW & After PSW \\
\hline Age (year) & $56.11(9.54)$ & & $55.87(8.16)$ & & 0.026 & $\approx 0$ \\
\hline \multicolumn{7}{|l|}{ Sex } \\
\hline Female & 1 & (2) & 10 & $(5)$ & 0.188 & $\approx 0$ \\
\hline Male & 55 & (98) & 181 & (95) & & \\
\hline \multicolumn{7}{|l|}{ Residency } \\
\hline Non-north & 39 & $(70)$ & 123 & $(64)$ & 0.112 & $\approx 0$ \\
\hline North & 17 & (30) & 68 & $(36)$ & & \\
\hline \multicolumn{7}{|l|}{ Drinking } \\
\hline No & 14 & $(25)$ & 20 & $(10)$ & 0.387 & $\approx 0$ \\
\hline Yes & 42 & (75) & 171 & $(90)$ & & \\
\hline \multicolumn{7}{|l|}{ Smoking } \\
\hline No & 6 & (11) & 17 & (9) & 0.061 & $\approx 0$ \\
\hline Yes & 50 & (89) & 174 & $(91)$ & & \\
\hline \multicolumn{7}{|l|}{ PET } \\
\hline No & 41 & (73) & 67 & (35) & 0.828 & $\approx 0$ \\
\hline Yes & 15 & $(27)$ & 124 & $(65)$ & & \\
\hline \multicolumn{7}{|l|}{ Tumor location } \\
\hline Non-cervical & 51 & (91) & 163 & (85) & 0.178 & $\approx 0$ \\
\hline Cervical & 5 & (9) & 28 & (15) & & \\
\hline \multicolumn{7}{|l|}{ N-stage } \\
\hline 0 & 4 & (7) & 17 & (9) & 0.065 & $\approx 0$ \\
\hline $1-3$ & 52 & (93) & 174 & (91) & & \\
\hline BMI & $19.30(3.16)$ & & 20.75 (3.69) & & 0.424 & $\approx 0$ \\
\hline
\end{tabular}

BMI body mass index, C/T chemotherapy, dCCRT definitive concurrent chemoradiotherapy, PET positron emission tomography, PSW propensity-score weighting, SD standard deviation

a Rounded

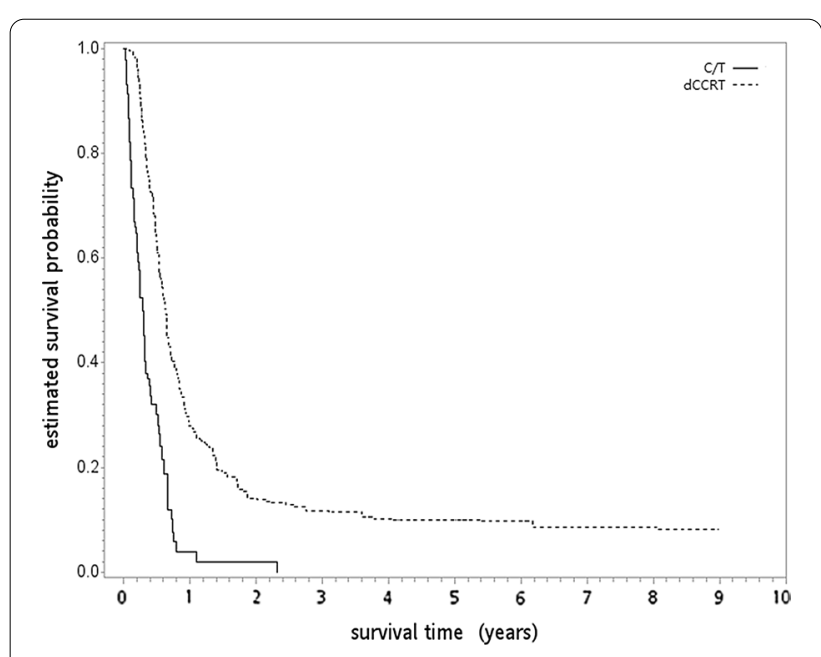

Fig. 2 The overlap weight-adjusted overall survival curve (in years) in the primary analysis. $C / T$ chemotherapy, $d C C R T$ definitive concurrent nonrandomized nature, and RCTs are needed for confirmation. However, no RCTs were included in a recent relevant systematic review [30]. When we further searched the trial registry (https://clinicaltrials.gov/) in Dec 2020, we did not find relevant RCTs. Therefore, we believe our study provides useful evidence regarding radiotherapy for cT4bNanyM0 ESqCC while more studies on this topic are awaited.

There were also limitations in our study. First, as with all nonrandomized studies, potential unmeasured confounder(s) such as patient performance status, biomarkers [31] or radiotherapy tolerability were not available due to data limitations, although we used the PS approach to balance observed covariates and reported the E-value to assess the potential impact of potential unmeasured confounder(s). Second, cT4b patients were not a homogenous population. Some subgroups, such as those with vertebral body invasion, may not be the 
Table 2 Patient characteristics in SA-1: dCCRT with a low dose (<50 Gy)

\begin{tabular}{|c|c|c|c|c|c|c|}
\hline & \multicolumn{2}{|l|}{$C / T(n=56)$} & \multicolumn{2}{|c|}{ dCCRT with low dose $[<50 \mathrm{~Gy}](n=29)$} & \multicolumn{2}{|c|}{$\begin{array}{l}\text { Standardized difference } \\
\text { (rounded) }^{\mathrm{a}}\end{array}$} \\
\hline & Number or mean (SD) ${ }^{\mathrm{a}}$ & $\overline{(\%)^{\mathrm{a}}}$ & Number or mean (SD) ${ }^{\mathrm{a}}$ & $(\%)^{a}$ & Before PSW & After PSW \\
\hline Age (year) & $56.11(9.54)$ & & $54.86(6.90)$ & & 0.150 & $\approx 0$ \\
\hline \multicolumn{7}{|l|}{ Sex } \\
\hline Female & 1 & $(2)$ & 3 & $(10)$ & 0.364 & $\approx 0$ \\
\hline Male & 55 & $(98)$ & 26 & $(90)$ & & \\
\hline \multicolumn{7}{|l|}{ Residency } \\
\hline Non-north & 39 & $(70)$ & 19 & $(66)$ & 0.088 & $\approx 0$ \\
\hline North & 17 & $(30)$ & 10 & (34) & & \\
\hline \multicolumn{7}{|l|}{ Drinking } \\
\hline No & 14 & $(25)$ & 2 & (7) & 0.510 & $\approx 0$ \\
\hline Yes & 42 & $(75)$ & 27 & (93) & & \\
\hline \multicolumn{7}{|l|}{ Smoking } \\
\hline No & 6 & $(11)$ & 1 & (3) & 0.286 & $\approx 0$ \\
\hline Yes & 50 & (89) & 28 & (97) & & \\
\hline \multicolumn{7}{|l|}{ PET } \\
\hline No & 41 & (73) & 8 & $(28)$ & 1.026 & $\approx 0$ \\
\hline Yes & 15 & $(27)$ & 21 & $(72)$ & & \\
\hline \multicolumn{7}{|l|}{ Tumor location } \\
\hline Non-cervical & 51 & $(91)$ & 26 & (90) & 0.048 & $\approx 0$ \\
\hline cervical & 5 & (9) & 3 & (10) & & \\
\hline \multicolumn{7}{|l|}{ N-stage } \\
\hline 0 & 4 & (7) & 1 & (3) & 0.166 & $\approx 0$ \\
\hline $1-3$ & 52 & (93) & 28 & (97) & & \\
\hline BMI & $19.30(3.16)$ & & $20.83(3.91)$ & & 0.430 & $\approx 0$ \\
\hline
\end{tabular}

$B M I$ body mass index, $C / T$ chemotherapy, $d C C R T$ definitive concurrent chemoradiotherapy, PET positron emission tomography, PSW propensity-score weighting, SA subgroup analyses, $S D$ standard deviation

a Rounded

ideal study population [3], but this could not be clarified in our study due to the retrospective nature and data limitations. Third, the use of salvage therapy may have impacted our primary endpoint (OS) but could not be evaluated due to data limitations in the TCR. Fourth, some researchers used neoadjuvant $\mathrm{C} / \mathrm{T}$ 1st, followed by planned local treatment (usually surgery for those responsive and resectable, or CCRT for the others) [12, 32]. This strategy was not recommended by the North American treatment guidelines for cT4b ESqCC [3] and may not lead to significantly better outcomes (see the Additional file 1 and the Additional file 2), although the results from ongoing RCTs are eagerly awaited [12]. However, due to data limitations, our study was unable to exactly exclude those who were planned for this neoadjuvant $\mathrm{C} / \mathrm{T}$ strategy but did not take local treatment (probably due to poor response on neoadjuvant $\mathrm{C} / \mathrm{T}$ ), so our results in the $\mathrm{C} / \mathrm{T}$ group may be biased and underestimated. Fifth, other endpoints [such as quality of life or toxicity (especially fistula) in addition to OS used in our study] might also be relevant, but these were not included in our study due to data limitations. Finally, this study was based on patients treated in Taiwan within the period from 2011 to 2017, so the implications for other population(s) with different covariate distributions are not clear. Furthermore, the impact of new systemic therapies, such as immunotherapy, could not be evaluated [33]. 
Table 3 Patient characteristics in SA-2: dCCRT with a standard dose (50-70 Gy)

\begin{tabular}{|c|c|c|c|c|c|c|}
\hline & \multicolumn{2}{|l|}{$C / T(n=56)$} & \multicolumn{2}{|c|}{$\begin{array}{l}\text { dCCRT with standard dose [50-70 Gy] } \\
(n=162)\end{array}$} & \multicolumn{2}{|c|}{$\begin{array}{l}\text { Standardized difference } \\
\text { (rounded) }^{\mathrm{a}}\end{array}$} \\
\hline & Number or mean $(S D)^{a}$ & $(\%)^{a}$ & Number or mean $(S D)^{a}$ & $(\%)^{a}$ & Before PSW & After PSW \\
\hline Age (year) & $56.11(9.54)$ & & $56.06(8.37)$ & & 0.006 & $\approx 0$ \\
\hline \multicolumn{7}{|l|}{ Sex } \\
\hline Female & 1 & $(2)$ & 7 & (4) & 0.148 & $\approx 0$ \\
\hline Male & 55 & (98) & 155 & (96) & & \\
\hline \multicolumn{7}{|l|}{ Residency } \\
\hline Non-north & 39 & $(70)$ & 104 & $(64)$ & 0.116 & $\approx 0$ \\
\hline North & 17 & (30) & 58 & $(36)$ & & \\
\hline \multicolumn{7}{|l|}{ Drinking } \\
\hline No & 14 & $(25)$ & 18 & $(11)$ & 0.367 & $\approx 0$ \\
\hline Yes & 42 & $(75)$ & 144 & $(89)$ & & \\
\hline \multicolumn{7}{|l|}{ Smoking } \\
\hline No & 6 & $(11)$ & 16 & $(10)$ & 0.028 & $\approx 0$ \\
\hline Yes & 50 & (89) & 146 & $(90)$ & & \\
\hline \multicolumn{7}{|l|}{ PET } \\
\hline No & 41 & (73) & 59 & $(36)$ & 0.796 & $\approx 0$ \\
\hline Yes & 15 & $(27)$ & 103 & $(64)$ & & \\
\hline \multicolumn{7}{|l|}{ Tumor location } \\
\hline Non-cervical & 51 & $(91)$ & 137 & $(85)$ & 0.200 & $\approx 0$ \\
\hline cervical & 5 & (9) & 25 & (15) & & \\
\hline \multicolumn{7}{|l|}{$\mathrm{N}$-stage } \\
\hline 0 & 4 & (7) & 16 & (10) & 0.098 & $\approx 0$ \\
\hline $1-3$ & 52 & (93) & 146 & (90) & & \\
\hline BMI & $19.30(3.16)$ & & $20.74(3.66)$ & & 0.422 & $\approx 0$ \\
\hline
\end{tabular}

$B M I$ body mass index, $C / T$ chemotherapy, $d C C R T$ definitive concurrent chemoradiotherapy, PET positron emission tomography, PSW propensity-score weighting, SA subgroup analyses, $S D$ standard deviation

a Rounded

Table 4 The HR of death for dCCRT versus $C / T$

\begin{tabular}{llll}
\hline $\mathrm{dCCRT}$ versus $\mathrm{C} / \mathrm{T}$ & Primary analyses: $\mathrm{dCCRT}$ (dose $\leq 70 \mathrm{~Gy})$ & SA-1: dCCRT with low dose (<50 Gy) & $\begin{array}{l}\text { SA-2: dCCRT with } \\
\text { standard dose } \\
(50-70 \mathrm{~Gy})\end{array}$ \\
\hline $\mathrm{HR}$ & & 1.1 & 0.31 \\
$95 \% \mathrm{Cl}$ & 0.36 & $0.56-2.15$ & $0.21-0.48$ \\
$P$ value & $0.24-0.53$ & 0.79 & $<0.001$ \\
\hline
\end{tabular}

$C /$ confidence interval, $C / T$ chemotherapy, $d C C R T$ definitive concurrent chemoradiotherapy, HR hazard ratio

\section{Conclusions}

In this population-based nonrandomized study of cT4bNanyM0 esophageal squamous cell carcinoma patients from Asia (Taiwan), we found that the use of radiotherapy with chemotherapy was associated with better overall survival than chemotherapy alone. Further studies (especially RCTs) are needed to confirm our findings.

Abbreviations

AJCC: American Joint Committee on Cancer; BMI: Body mass index; C/T: Chemotherapy; dCCRT: Definitive concurrent chemoradiotherapy; HR: Hazard 
ratio; IECM: Incidence of esophageal cancer mortality; LA-ESqCC: Locally advanced esophageal squamous cell carcinoma; OS: Overall survival; PET: Positron emission tomography; PS: Propensity score; PSW: Propensity score weighting; SA: Subgroup analyses; SDif: Standardized difference; TCR: Taiwan Cancer Registry; 95\% Cl: 95\% Confidence interval.

\section{Supplementary Information}

The online version contains supplementary material available at https://doi. org/10.1186/s12876-021-01742-4.

Additional file 1: Patient characteristics of the study population when nCT was compared to dCCRT.

Additional file 2: The overlap weight-adjusted overall survival curve (in years) when nCT was compared to dCCRT for patients in Additional file 1.

\section{Acknowledgements}

This work was funded by the Health Promotion Administration, Ministry of Health and Welfare (Grant No. A1081116). Funded by Tobacco Health and Welfare Taxation. The content of this research may not represent the opinion of the Health Promotion Administration, Ministry of Health and Welfare. We thank American Journal Experts for their professional English-language editing of this manuscript.

\section{Authors' contributions}

CRC participated in the concept and design, analysis and interpretation of data, and drafting of the manuscript. CYC, YHC, CJH, and HYK participated in the concept and design, interpretation of data, and drafting of the manuscript. $\mathrm{CCL}$ participated in the concept and design, analysis of data and drafting of the manuscript. All authors read and approved the final manuscript.

\section{Funding}

We are grateful to the Department of Medical Research at China Medical University Hsinchu Hospital (CMUHCH-DMR-109-015, CMUHCH-DMR-110-015) for providing administrative and funding support.

\section{Availability of data and materials}

The analyzed datasets of this study are not publicly available due to restrictions apply and will not be made available from the corresponding author on request.

\section{Declarations}

\section{Ethics approval and consent to participate}

All methods were carried out in accordance with relevant guidelines and regulations. All study participants in the Taiwan Cancer Registry were deidentified so that the review committee had waived our study from the requirement of participants' informed consent. All experimental protocols were approved by the National Health Research Institute (EC1090502-E).

\section{Consent for publication}

Not applicable.

\section{Competing interests}

The authors declare that they have no competing interests.

\footnotetext{
Author details

1 Department of Radiation Oncology, China Medical University Hsinchu Hospital, Hsinchu, Taiwan. ${ }^{2}$ Division of Thoracic Surgery, Department of Surgery, Chung Shan Medical University Hospital, Taichung, Taiwan. ${ }^{3}$ Institute of Medicine, Chung Shan Medical University, Taichung, Taiwan. ${ }^{4}$ Department of Medical Imaging and Radiological Sciences, Chung Shan Medical University, Taichung, Taiwan. ${ }^{5}$ Department of Radiation Oncology, Chung Shan Medical University Hospital, Taichung, Taiwan. ${ }^{6}$ Department of Radiation Oncology, Kaohsiung Medical University Hospital, Kaohsiung, Taiwan. ${ }^{7}$ National Institute of Cancer Research, National Health Research Institutes, Miaoli, Taiwan. ${ }^{8}$ Department of Healthcare Administration, Asia University, Taichung, Taiwan. ${ }^{9}$ Department of Radiation Oncology, China Medical University Hospital,
}

Taichung, Taiwan. ${ }^{10}$ School of Medicine, College of Medicine, China Medical University, No. 91 Hsueh-Shih Road, North District, Taichung 40402, Taiwan.

Received: 21 January 2021 Accepted: 26 March 2021

Published online: 07 April 2021

\section{References}

1. Lagergren J, Smyth E, Cunningham D, Lagergren P. Oesophageal cancer. Lancet. 2017:390(10110):2383-96.

2. Chien CR, Lin CY, Chen CY. Re: Incidence of adenocarcinoma of the esophagus among white Americans by sex, stage, and age. J Natl Cancer Inst. 2009;101(20):1428 (author reply 1429).

3. National Comprehensive Cancer Network Guidelines for Esophageal and Esophagogastric Junction Cancers, version 4.2020. https://www.nccn. org/professionals/physician_gls/pdf/esophageal.pdf. Accessed 22 Oct 2020.

4. Lordick F, Mariette C, Haustermans K, Obermannová R, Arnold D. Oesophageal cancer: ESMO clinical practice guidelines. Ann Oncol. 2016;27(suppl 5):v50-7.

5. Kitagawa Y, Uno T, Oyama T, et al. Esophageal cancer practice guidelines 2017 edited by the Japan esophageal society: part 2. Esophagus. 2019;16(1):25-43.

6. Shamji FM, Inculet R. Management of malignant tracheoesophageal fistula. Thorac Surg Clin. 2018;28(3):393-402.

7. Cushman TR, Shaaban SG, Moreno AC, Lin C, Verma V. Management of unresectable T4b esophageal cancer: practice patterns and outcomes from the national cancer data base. Am J Clin Oncol. 2019;42(2):154-9.

8. Chiang CJ, You SL, Chen CJ, Yang YW, Lo WC, Lai MS. Quality assessment and improvement of nationwide cancer registration system in Taiwan: a review. Jpn J Clin Oncol. 2015;45(3):291-6.

9. Chiang CJ, Wang YW, Lee WC. Taiwan's nationwide cancer registry system of 40 years: past, present, and future. J Formos Med Assoc. 2019;118(5):856-8.

10. Li CC, Chen CY, Chien CR. Comparative effectiveness of image-guided radiotherapy for non-operated localized esophageal squamous cell carcinoma patients receiving concurrent chemoradiotherapy: a population-based propensity score matched analysis. Oncotarget. 2016;7(44):71548-55.

11. Hirano $\mathrm{H}$, Boku N. The current status of multimodality treatment for unresectable locally advanced esophageal squamous cell carcinoma. Asia Pac J Clin Oncol. 2018;14(4):291-9.

12. Terada $\mathrm{M}$, Hara $\mathrm{H}$, Daiko $\mathrm{H}$, et al. Phase III study of tri-modality combination therapy with induction docetaxel plus cisplatin and 5-fluorouracil versus definitive chemoradiotherapy for locally advanced unresectable squamous-cell carcinoma of the thoracic esophagus (JCOG1510: TRIANgLE). Jpn J Clin Oncol. 2019;49(11):1055-60.

13. Kuo YH, Fang HY, Lin YS, et al. Effectiveness of image-guided radiotherapy for locally advanced esophageal squamous cell carcinoma patients treated with definitive concurrent chemoradiotherapy. Thorac Cancer. 2020;11(1):113-9.

14. Li CC, Fang HY, Lin CY, Shen WC, Chien CR. Outcomes of localized esophageal squamous cell carcinoma patients treated with definitive concurrent chemoradiotherapy using either standard or high radiotherapy dose: a retrospective study controlling for organ at risk dose. Anticancer Res. 2019;39(1):511-7

15. Webster-Clark M, Stürmer T, Wang TS, et al. Using propensity scores to estimate effects of treatment initiation decisions: state of the science. Stat Med. 2021;40(7):1718-35.

16. Lalani N, Jimenez RB, Yeap B. Understanding propensity score analyses. Int J Radiat Oncol Biol Phys. 2020;107(3):404-7.

17. Booth CM, Karim S, Mackillop WJ. Real-world data: towards achieving the achievable in cancer care. Nat Rev Clin Oncol. 2019;16(5):312-25.

18. Austin PC. The use of propensity score methods with survival or time-toevent outcomes: reporting measures of effect similar to those used in randomized experiments. Stat Med. 2014;33(7):1242-58.

19. Mao H, Li L, Greene T. Propensity score weighting analysis and treatment effect discovery. Stat Methods Med Res. 2019;28(8):2439-54. 
20. Ali MS, Groenwold RHH, Belitser SV, et al. Reporting of covariate selection and balance assessment in propensity score analysis is suboptimal: a systematic review. J Clin Epidemiol. 2015;68(2):112-21.

21. Garrido MM, Kelley AS, Paris J, et al. Methods for constructing and assessing propensity scores. Health Serv Res. 2014;49(5):1701-20.

22. Cole SR, Hernán MA. Adjusted survival curves with inverse probability weights. Comput Methods Programs Biomed. 2004;75(1):45-9.

23. Austin PC. Variance estimation when using inverse probability of treatment weighting (IPTW) with survival analysis. Stat Med. 2016;35(30):5642-55.

24. Zhang X, Stamey JD, Mathur MB. Assessing the impact of unmeasured confounders for credible and reliable real-world evidence. Pharmacoepidemiol Drug Saf. 2020;29(10):1219-27.

25. Haneuse S, VanderWeele TJ, Arterburn D. Using the E-value to assess the potential effect of unmeasured confounding in observational studies. JAMA. 2019;321(6):602-3.

26. VanderWeele TJ, Ding P. Sensitivity analysis in observational research: introducing the E-value. Ann Intern Med. 2017;167(4):268-74.

27. Bolch CA, Chu H, Jarosek S, Cole SR, Elliott S, Virnig B. Inverse probability of treatment-weighted competing risks analysis: an application on longterm risk of urinary adverse events after prostate cancer treatments. BMC Med Res Methodol. 2017;17(1):93.

28. Stahl M, Stuschke M, Lehmann N, et al. Chemoradiation with and without surgery in patients with locally advanced squamous cell carcinoma of the esophagus. J Clin Oncol. 2005;23(10):2310-7.
29. Bedenne L, Michel P, Bouché O, et al. Chemoradiation followed by surgery compared with chemoradiation alone in squamous cancer of the esophagus: FFCD 9102. J Clin Oncol. 2007;25(10):1160-8.

30. Makino T, Yamasaki M, Tanaka K, et al. Treatment and clinical outcome of clinical T4 esophageal cancer: a systematic review. Ann Gastroenterol Surg. 2018;3(2):169-80.

31. Taylor RR, Surman DR, Diggs LP, Trepel JB, Lee MJ, Ryan J, Davis JL, Steinberg SM, Hernandez JM, Hoang C, Kenney CM, Bond CD, Kunst TF, Letai A, Schrump DS. Metabolomic and BH3 profiling of esophageal cancers: novel assessment methods for precision therapy. BMC Gastroenterol. 2018;18(1):94.

32. Miyata $\mathrm{H}$, Yamasaki M, Kurokawa $\mathrm{Y}$, et al. Clinical relevance of induction triplet chemotherapy for esophageal cancer invading adjacent organs. J Surg Oncol. 2012;106(4):441-7.

33. Kojima T, Shah MA, Muro K, et al. Randomized Phase III KEYNOTE-181 study of pembrolizumab versus chemotherapy in advanced esophageal cancer. J Clin Oncol. 2020;38(35):4138-48.

\section{Publisher's Note}

Springer Nature remains neutral with regard to jurisdictional claims in published maps and institutional affiliations.
Ready to submit your research? Choose BMC and benefit from:

- fast, convenient online submission

- thorough peer review by experienced researchers in your field

- rapid publication on acceptance

- support for research data, including large and complex data types

- gold Open Access which fosters wider collaboration and increased citations

- maximum visibility for your research: over 100M website views per year

At BMC, research is always in progress.

Learn more biomedcentral.com/submissions 